\title{
The antiemetic effect of midazolam or/and ondansetron added to intravenous patient controlled analgesia in patients of pelviscopic surgery
}

\author{
Dae Seong Kim, Gill Hoi Koo, Hyun Kang, Chong Wha Baek, Yong Hun Jung, Young Cheol Woo, \\ Jin Yun Kim, and Sun Gyoo Park \\ Department of Anesthesiology and Pain Medicine, College of Medicine, Chung-Ang University, Seoul, Korea
}

Background: We made a comparative study on the antiemetic effect of midazolam and ondansetron added to intravenous patient-controlled analgesia (PCA) using fentanyl with gynecologic patients undergoing pelviscopic surgery.

Methods: The PCA using $20 \mu \mathrm{g} / \mathrm{kg}$ of fentanyl was started in all groups postoperatively. A dose of $16 \mathrm{mg}$ of ondansetron was added to the PCA of group $\mathrm{O}(\mathrm{n}=30)$. A dose of $5 \mathrm{mg}$ of midazolam was added to the PCA of group $\mathrm{M}(\mathrm{n}=30)$. While $16 \mathrm{mg}$ of ondansetron and $5 \mathrm{mg}$ of midazolam were added to the PCA of group MO $(\mathrm{n}=30)$. Total volume of the PCA was $60 \mathrm{ml}$, and the PCA system was programmed to deliver $0.5 \mathrm{ml} / \mathrm{h}$ of continuous doses and a $0.5 \mathrm{ml}$ bolus on demand, with a 15 minutes lockout interval. The incidence of postoperative nausea and vomiting (PONV), sedation score, visual analog scale (VAS) for pain, and rescue drug dose for PONV were investigated at the postanesthesia care unit (PACU), 6 hours, and 24 hours after recovery.

Results: The incidence of PONV in group MO was significantly lower than in group O at PACU, 24 hours after recovery $(\mathrm{P}<0.05)$. The sedation score and VAS pain score showed no differences among all groups.

Conclusions: Midazolam added to PCA using fentanyl proved more effective than ondansetron in preventing PONV without adverse effects. (Korean J Anesthesiol 2012; 62: 343-349)

Key Words: Midazolam, Ondansetron, Patient-controlled analgesia, Postoperative nausea and vomiting.

Received: July 4, 2011. Revised: 1st, July 29, 2011; 2nd, September 1, 2011. Accepted: September 9, 2011.

Corresponding author: Gill Hoi Koo, M.D., Ph.D., Department of Anesthesiology and Pain Medicine, College of Medicine, Chung-Ang University, 224-1,Heukseok-1dong, Dongjak-gu, Seoul 156-756, Korea. Tel: 82-2-6299-2571, Fax: 82-2-6299-2585, E-mail: koogillhoi@hanafos.com (c) This is an open-access article distributed under the terms of the Creative Commons Attribution Non-Commercial License (http:// creativecommons.org/licenses/by-nc/3.0/), which permits unrestricted non-commercial use, distribution, and reproduction in any medium, provided the original work is properly cited. 


\section{Introduction}

Postoperative nausea and vomiting (PONV) is one of the most frequent postoperative complications, and its reported incidence rate is $20-30 \%$, despite the use of various antiemetic drugs [1]. PONV could reduce patients' postoperative satisfaction and cause severe complications and economic loss, allowed to continued.

Various factors could cause continuous PONV. Among them, intraoperative or postoperative use of opioids is a factor that can be controlled by the anesthesiologist; the frequency and intensity of PONV can be reduced by injecting an appropriate antiemetic. Intravenous patient-controlled analgesia (IVPCA) is used for postoperative pain control, but it may cause PONV because of the injected opioids. Ondansetron, a 5-hydroxytryptamine $\left(5-\mathrm{HT}_{3}\right)$ receptor antagonist, is widely used because it can prevent and treat PONV $[2,3]$ with a low incident rate of side effects commmoly caused by other antiemetics. However, it has been reported that this type of drug does not reduce PONV effectively [4], and that its usefulness is low considering to the price [5].

It was recently reported that midazolam, a benzodiazepine used for pretreatment to reduce preanesthetic anxiety, reduced the frequency and intensity of PONV, showing a sedative effect as well as an antiemetic effect $[6,7]$. Midazolam has been used in many different ways to prevent PONV. In a case where a mixture of midazolam and morphine was used while performing IV-PCA, the treatment was reported as effective and helpful in preventing PONV [8].

However, the combined administration of midazolam and ondansetron for PONV has not been reported internationally; thus, the aim of this study was to investigate the effect of the combined administration of midazolam and ondansetron on PONV.

\section{Materials and Methods}

The subjects of this study were patients classified as American Society of Anesthesiologists I and II, they were supposed to undergo general anesthesia and postoperative IVPCA for a pelviscopic gynecological surgery. They ranged in age from between 20 and 60 years old, and their body weight was between $50 \mathrm{~kg}$ and $70 \mathrm{~kg}$. Patients who had a history of smoking, those who had a history of PONV or kinesia, and those who were extremely obese with a body mass index (BMI) of 40 or higher were excluded from the study. Before conducting the study, participants were given an explanation about the purpose of the study and the side effects that might occur with the use of mixed opioids for IV-PCA, and their written consent was obtained. The incident rate of PONV was considered as the primary outcome measures of this study, and the degree of sedation and pain were investigated together.

As premedication for all the patients in the wards, $0.2 \mathrm{mg}$ of glycopyrrolate was intramuscularly injected 30 minutes before starting the anesthesia. Anesthesia was induced with $2 \mu \mathrm{g} / \mathrm{kg}$ of fentanyl, $5 \mathrm{mg} / \mathrm{kg}$ of thiopental, and $0.6 \mathrm{mg} / \mathrm{kg}$ of rocuronium. Following intubation, inhalation anesthesia was maintained with $\mathrm{N}_{2} \mathrm{O} 1.5 \mathrm{~L} / \mathrm{min}, \mathrm{O}_{2} 1.5 \mathrm{~L} / \mathrm{min}$, and sevoflurane of $2-3 \mathrm{vol} \%$. While maintaining anesthesia, the tidal volume was regulated to keep the end tidal $\mathrm{CO}_{2}$ pressure in the range of $30-35 \mathrm{mmHg}$. Sevoflurane of 1 vol\% was maintained around the time when the skin suture began, but the inhalation anesthetic was stopped at the end of the surgery. According to the mixed antiemetics, the subjects were divided into three groups: O Group, in which $16 \mathrm{mg}$ of ondansetron (Ondant Injection 8 mg ${ }^{\circledR}$, Hanmi Pharm, Seoul, Korea) was injected, the M Group, in which $5 \mathrm{mg}$ of midazolam (Bukwang Midazolam Injection ${ }^{\circledR}$, Bukwang Pharm, Seoul, Korea) was injected, and the MO Group, in which $16 \mathrm{mg}$ of ondansetron and $5 \mathrm{mg}$ of midazolam were mixed and injected. There was no difference in the age, weight, and height of the subjects among the groups (Table 1). The instrument used for IV-PCA was the Basal/Bolus Infusor (Baxter Healthcare Corporation, USA). Before starting anesthesia, $20 \mu \mathrm{g} / \mathrm{kg}$ of fentanyl and the respective antiemetic were mixed with a final solution volume of $60 \mathrm{ml}$, and infused into the patients. Continuous infusion was set at $0.5 \mathrm{ml} / \mathrm{h}$ with a bolus of $0.5 \mathrm{ml}$ and a lockout time of 15 minutes. Before conducting the study, midazolam and ondansetron were mixed in normal saline solution and it was verified that no crystal formed for two days by macroscopic and microscopic observation. Stewart et al. reported that the mixed infusion of ondansetron with midazolam and fentanyl was stable for 24 hours [9]. In a study by Chiaretti et al. [10], an effective result was achieved without any particular problems when fentanyl and midazolam were mixed and infused into PCA patients. Thus, the authors considered the mixed solution of fentanyl, ondansetron, and midazolam to be

Table 1. Demographic Data

\begin{tabular}{lccc}
\hline & $\begin{array}{c}\text { Group O } \\
(\mathrm{n}=30)\end{array}$ & $\begin{array}{c}\text { Group M } \\
(\mathrm{n}=30)\end{array}$ & $\begin{array}{c}\text { Group MO } \\
(\mathrm{n}=30)\end{array}$ \\
\hline Age $(\mathrm{yr})$ & $38.5 \pm 8.5$ & $38.0 \pm 10.3$ & $39.1 \pm 8.7$ \\
Weight $(\mathrm{kg})$ & $57.1 \pm 7.8$ & $56.1 \pm 7.3$ & $56.4 \pm 7.4$ \\
Height $(\mathrm{cm})$ & $159.0 \pm 4.1$ & $160.6 \pm 5.4$ & $158.5 \pm 5.4$ \\
Anesthesia time (min) & $116.3 \pm 80.9$ & $109.4 \pm 59.7$ & $121.6 \pm 67.9$ \\
PACU stay time (min) & $35.6 \pm 10.3$ & $31.1 \pm 10.8$ & $44.0 \pm 28.9$ \\
\hline
\end{tabular}

Values are mean \pm SD. A $16 \mathrm{mg}$ dose of ondansetron is added to the PCA of group O; $5 \mathrm{mg}$ of midazolam is added to the PCA of group $\mathrm{M}$; and $16 \mathrm{mg}$ of ondansetron and $5 \mathrm{mg}$ of midazolam are added to the PCA of group MO. There are no significant differences among the groups. PACU: postanesthesia care unit, PCA: patient controlled analgesia. 
safe and physicochemically stable. About 30 minutes before the end of the surgery, a bolus of $8 \mathrm{mg}$ of ondansetron was intravenously injected, and $0.4 \mathrm{mg}$ of glycopyrrolate and $20 \mathrm{mg}$ of pyridostigmine were mixed and intravenously injected in order to reverse the muscular relaxation.

At least one incident of nausea or vomiting was considered as an incidence of PONV, and the PONV incidence rate was investigated for three periods of time: recovery room, from the time of recovery to the first 6 hours after coming out of the recovery room, and between 6 and 24 hours after recovery. When a patient complained of PONV, $8 \mathrm{mg}$ of ondansetron was intravenously injected, and it was then verified whether PONV was relieved by observing the patient for five minutes. If the patient complained of PONV continuously, $10 \mathrm{mg}$ of metoclopramide was intravenously injected. If the patient complained of PONV despite that, an intravenous injection of $5 \mathrm{mg}$ of dexamethasone was given. Sedation was assessed with the modified observer's assessment of alertness/sedation (OAA/ S) score [11] (Table 2). If the OAA/S score was 3 or lower, or if the tidal rate was 10 times per minute or lower, or if the oxygen saturation was $90 \%$ or lower, flumazenil, an antagonist of benzodiazepine, was injected. The pain was assessed using the visual analog scale (VAS, $0-10$ ). Intravenous injection of $30 \mathrm{mg}$ of ketorolac was done when the VAS was 5 or higher or when the patient complained of severe pain.

After the end of the surgery, when the patient recovered consciousness in the recovery room, the PONV incidence, the $\mathrm{OAA} / \mathrm{S}$ score, and the VAS were measured. The PONV incidence, the OAA/S score, the VAS, and the number of ondansetron, metoclopramide, dexamethasone and ketorolac injections were recorded by visiting the patients at 6 hours and 24 hours after the recovery, by interviewing the patients as well as their caregivers, and by reviewing the clinical chart. All the investigations were done by a rater who was not aware of the classification of the groups.

Individual measurements were expressed as the percentage of the number of patients (\%) and the "mean \pm standard deviation", and analyzed with SPSS 18.0. For the continuous variables, normality was tested by the Shapiro-Wilk test. If the distribution was normal, an ANOVA was done and a Tukey test

Table 2. Responsiveness Scores of the Modified Observer's Assessment of Alertness/Sedation Scale

\begin{tabular}{lc}
\hline \multicolumn{1}{c}{ Response } & Score level \\
\hline Responds readily to name spoken in normal tone & 5 (Alert) \\
Lethargic response to name spoken in normal tone & 4 \\
Responds only after name is called loudly or repeatedly & 3 \\
Responds only after mild prodding or shaking & 2 \\
Does not respond to mild prodding or shaking & 1 \\
Does not respond to noxious stimuli & 0 \\
\hline
\end{tabular}

was done to compare among the groups. If the distribution was not normal, a Kruskal-Wallis test was done and a Bonferroni correction was done to compare among the groups. For the discrete variables, a Chi-square test or a Fisher's exact test was done, if necessary. The number of subjects was determined by referring to the study by Park and Cho. The PONV incidence rate of the $\mathrm{O}$ group was $66.7 \%$ [12]. Assuming that the PONV incidence rate of the $\mathrm{O}$ group in this study was equal to that of the previous study, the PONV incidence rate of the M Group and the MO group was set as $33.35 \%$. The number of samples for each group was 27 calculated by on-sided test on the basis of a significance level of $5 \%$ and a power of test of $80 \%$. The total number of subjects was 90 , assuming a loss rate of $10 \%$ for the follow-up observation.

\section{Results}

There was no difference in the anesthetic time and the delayed time in the recovery room (Table 1). The postoperative PONV incidence rate measured in the recovery room was $43.3 \%$ (13 subjects) in the $\mathrm{O}$ group, $16.7 \%$ (5 subjects) in the $\mathrm{M}$ group, and $16.7 \%$ ( 5 subjects) in the MO group, with a significantly lower incidence rate in the $\mathrm{M}$ and $\mathrm{MO}$ groups than in the $\mathrm{O}$ group $(\mathrm{P}<0.05)$. The PONV incidence rate of the MO group was significantly lower than that of the $\mathrm{O}$ group, from the time of leaving the recovery room to the first 6 hours after leaving the recovery room $(\mathrm{P}<0.05)$. However, no significant difference was found among the groups from 6 hours after leaving the recovery room to 24 hours after. The overall PONV incidence rate from the recovery room until 24 hours after leaving the recovery room was $63.3 \%$ ( 19 subjects) in the O group, $46.7 \%$ (14 subjects) in the M group, and 33.3\% (10 subjects) in the MO group. The overall PONV incidence rate of the MO group was significantly lower than that of the $\mathrm{O}$ group $(\mathrm{P}<0.05)$ (Fig. 1).

The percentage of the patients who experienced nausea or vomiting during the time after leving the recovery room until 24 hours after recovery and thus, required additional antiemetic was the highest in the O Group at 53.3\% (16 subjects), followed by the MO group at $33.3 \%$ (10 subjects) and the M Group at 26.7 (8 subjects). The percentage of the patients who showed continued PONV and thus, to whom antiemetics, ondansetron, metoclopramide or dexamethasone, were injected two times or more was $37.5 \%$ ( 6 subjects) in the O Group, $12.5 \%$ ( 1 subject) in the M Group, and $40 \%$ (4 subjects) in the MO group (Table 3).

There was no difference in the OAA/S score over time among the groups at the time when the subjects were in the recovery room and during the time until 6 hours and 24 hours after the leaving recovery room (Table 4 ). No subjects had an OAA/S score of 3 or lower or respiratory failure either in the recovery room or in the ward for 24 hours after leaving the recovery 


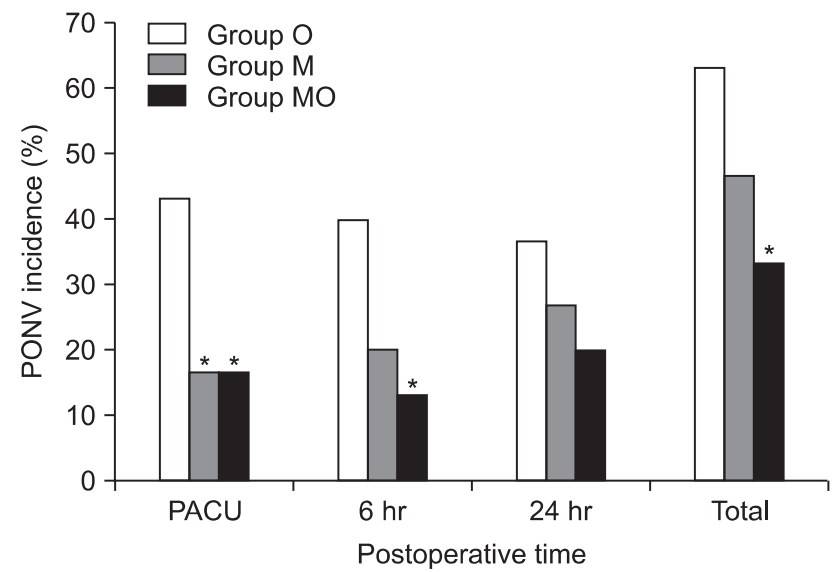

Fig. 1. The incidence of PONV at each postoperative time interval is shown. Value are numbers (\%) of patients. Ondansetron $16 \mathrm{mg}$ is added to PCA of group O. Midazolam $5 \mathrm{mg}$ is added to PCA of group $\mathrm{M}$. Ondansetron $16 \mathrm{mg}$ and midazolam $5 \mathrm{mg}$ are added to PCA of group MO. $\mathrm{P}<0.05$ is considered statistically significant. $* \mathrm{P}<0.05$ is compared with Group O. PONV: postoperative nausea and vomiting, PCA: patient controlled analgesia.

Table 3. Rescue Medications

\begin{tabular}{|c|c|c|c|}
\hline & $\begin{array}{l}\text { Group O } \\
(\mathrm{n}=30)\end{array}$ & $\begin{array}{l}\text { Group M } \\
(\mathrm{n}=30)\end{array}$ & $\begin{array}{c}\text { Group MO } \\
(\mathrm{n}=30)\end{array}$ \\
\hline Antiemetic agent & $16(53.3 \%)$ & $8(26.7 \%)$ & $10(33.3 \%)$ \\
\hline $\begin{array}{l}\text { Antiemetic agent } \\
\text { (Above twice) }\end{array}$ & $6(37.5 \%)$ & $1(12.5 \%)$ & $4(40 \%)$ \\
\hline Ketorolac & $8(26.6 \%)$ & $6(20 \%)$ & $10(33.3 \%)$ \\
\hline Flumazenil & $0(0 \%)$ & $0(0 \%)$ & $0(0 \%)$ \\
\hline
\end{tabular}

Values are numbers (\%) of patients. A $16 \mathrm{mg}$ of ondansetron is added to the PCA of group O; $5 \mathrm{mg}$ of midazolam is added to the PCA of group $\mathrm{M} ; 16 \mathrm{mg}$ of ondansetron and $5 \mathrm{mg}$ of midazolam are added to the PCA of group MO. Antiemetic agent: ondansetron, metoclopramide and dexamethasone. PCA: patient-controlled analgesia.

room.

There was no difference in the VAS score among the groups at the time when the subjects were in the recovery room and during the time until 6 hours and 24 hours after leaving the recovery room (Fig. 2). The percentage of patients to whom ketorolac was injected for severe pain was $26.6 \%$ (8 subjects) in the O Group, 20\% (6 subjects) in the M group, and 33.3\% (10 subjects) in the MO group (Table 3).

\section{Discussion}

In a recent study, five risk factors of the Korean PONV model were listed as: female gender, history of PONV or kinesia, nonsmoking, surgery longer than one hour, and use of opioids combined with IV-PCA. As the number of risk factors increased from 0 to 5 , the mean expected incidence rate of PONV increased from $12.7 \%$ to $19.9 \%, 29.3 \%, 40.7 \%, 53.1 \%$, and

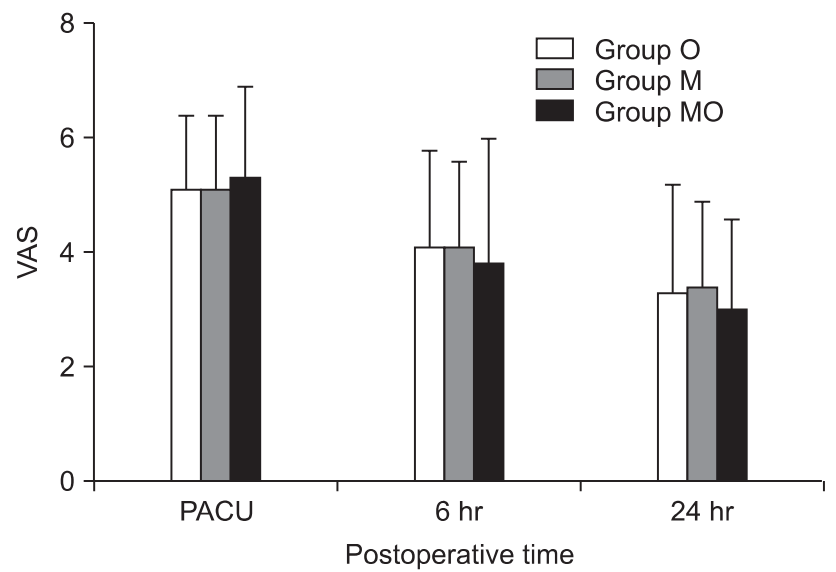

Fig. 2. VAS pain scores at each postoperative time interval is shown. The VAS pain scores decrease with time in all groups, but there are no significant differences among the groups. Value are mean \pm SD. Ondansetron $16 \mathrm{mg}$ is added to PCA of group O. Midazolam $5 \mathrm{mg}$ is added to PCA of group M. Ondansetron $16 \mathrm{mg}$ and midazolam 5 mg are added to PCA of group MO. VAS: visual analog scale, PCA: patient controlled analgesia.

Table 4. Degree of Sedation

\begin{tabular}{|c|c|c|c|}
\hline & $\begin{array}{l}\text { Group O } \\
(\mathrm{n}=30)\end{array}$ & $\begin{array}{c}\text { Group M } \\
(\mathrm{n}=30)\end{array}$ & $\begin{array}{l}\text { Group MO } \\
\qquad(\mathrm{n}=30)\end{array}$ \\
\hline \multicolumn{4}{|c|}{ Score (PACU) } \\
\hline 5 & $12(40 \%)$ & $12(40 \%)$ & $17(56.7 \%)$ \\
\hline 4 & $18(60 \%)$ & $18(60 \%)$ & $13(43.3 \%)$ \\
\hline 3 & $0(0 \%)$ & $0(0 \%)$ & $0(0 \%)$ \\
\hline 2 & $0(0 \%)$ & $0(0 \%)$ & $0(0 \%)$ \\
\hline 1 & $0(0 \%)$ & $0(0 \%)$ & $0(0 \%)$ \\
\hline 0 & $0(0 \%)$ & $0(0 \%)$ & $0(0 \%)$ \\
\hline \multicolumn{4}{|c|}{ Score (6 hr) } \\
\hline 5 & $16(53.3 \%)$ & $12(40 \%)$ & $19(63.3 \%)$ \\
\hline 4 & $14(46.7 \%)$ & $18(60 \%)$ & $11(36.7 \%)$ \\
\hline 3 & $0(0 \%)$ & $0(0 \%)$ & $0(0 \%)$ \\
\hline 2 & $0(0 \%)$ & $0(0 \%)$ & $0(0 \%)$ \\
\hline 1 & $0(0 \%)$ & $0(0 \%)$ & $0(0 \%)$ \\
\hline 0 & $0(0 \%)$ & $0(0 \%)$ & $0(0 \%)$ \\
\hline \multicolumn{4}{|c|}{ Score $(24 \mathrm{hr})$} \\
\hline 5 & $25(83.3 \%)$ & $21(70 \%)$ & $21(70 \%)$ \\
\hline 4 & $5(16.7 \%)$ & $9(30 \%)$ & $9(30 \%)$ \\
\hline 3 & $0(0 \%)$ & $0(0 \%)$ & $0(0 \%)$ \\
\hline 2 & $0(0 \%)$ & $0(0 \%)$ & $0(0 \%)$ \\
\hline 1 & $0(0 \%)$ & $0(0 \%)$ & $0(0 \%)$ \\
\hline 0 & $0(0 \%)$ & $0(0 \%)$ & $0(0 \%)$ \\
\hline
\end{tabular}

Values are numbers(\%) of patients. A $16 \mathrm{mg}$ of ondansetron is added to the PCA of group O; $5 \mathrm{mg}$ of midazolam is added to the PCA of group M; $16 \mathrm{mg}$ of ondansetron and $5 \mathrm{mg}$ of midazolam are added to the PCA of group MO. The degree of sedation is scored by modified observer's assessment of alertness/sedation scale. There are no significant differences among the groups.

$65.4 \%$, respectively [13]. Each type of surgery had a different PONV incidence rate: the PONV incidence rate was high in gynecologic surgery, laparoscopic surgery, abdominal surgery, augmentation mammoplasty, strabismus surgery, ENT surgery, 
surgery of the testis, and surgery of the shoulder [14]. In our study, patients who had a past history of smoking, PONV, or kinesia were excluded, and those who were to undergo a pelviscopic gynecological surgery were included as study subjects. The estimated PONV incidence rate in this study from the Korean PONV model was 53.1\%. The PONV incidence rate of the $\mathrm{O}, \mathrm{M}$, and MO groups when the patients were in the recovery room was $43.3 \%, 16.7 \%$, and $16.7 \%$, respectively. The PONV incidence rate of the $\mathrm{O}, \mathrm{M}$, and $\mathrm{MO}$ groups from the time of the recovery room to 24 hours after leaving the recovery room was $63.3 \%, 46.7 \%, 33.3 \%$, respectively. The PONV incidence rate when the patients were in the recovery room was lower than expected in all the groups, but that of the O Group for 24 hours after leaving the recovery room was $63.3 \%$, higher than $53.1 \%$, which was the incidence rate expected from the Korean PONV model.

IV-PCA, which is used for postoperative pain control, may increase the overall satisfaction of the patients by minimizing respiratory failure, reducing respiratory system complications, and enhancing the analgesic effect [15], but it may also increase the frequency and intensity of PONV when combined with the opioids [16]. However, PONV occurrence because of the use of an opioid combined with IV-PCA can be prevented by the use an appropriate antiemetic, and serotonin antagonists that selectively antagonize $5-\mathrm{HT}_{3}$ receptor are often used.

Different from other 5-hydroxytryptamine (5-HT) receptors, the $5-\mathrm{HT}_{3}$ receptor is a ligand-gated cation channel that is controlled by the ligand belonging to the nicotine $/ \gamma$-aminobutyric acid (GABA) receptor. The serotonin antagonists that selectively antagonize the $5-\mathrm{HT}_{3}$ receptor do not have a specific reaction to other 5-HT receptor subtypes and thus have the advantage of having no extrapyramidal side effects with drugs such as metoclopramide or droperidol. Among them, ondansetron not only treats vomiting due to cancer chemotherapy but also effectively treats and prevents PONV, although it has mild side effects such as headache, constipation, dizziness, and increased values in liver function tests [17]. In a study by Kim et al. [2], 4 mg of ondansetron preventively injected before the start of IVPCA decreased the incidence rate of PONV. Boonmak et al. [18] continuously infused morphine mixed with $0.2 \mathrm{mg} / \mathrm{ml}$ of ondansetron for IV-PCA and reported that the PONV incidence rate was effectively reduced. Hwang et al. [19] continuously performed IV-PCA combined with $8 \mathrm{mg}$ of ondansetron and reported that the incidence rate of postoperative nausea decreased. On the contrary, Kil et al. [20] asserted that injection of expensive ondansetron is less cost-effective than the injection of droperidol. Tramer et al. [21] reported that the preventive intravenous injection of $8 \mathrm{mg}$ of ondansetron or oral administration of $16 \mathrm{mg}$ was effective on postoperative vomiting but the effect was not clearly seen for nausea. In our study, the
PONV incidence rate of the O Group for 24 hours after the surgery was $63.3 \%$, higher than $53.1 \%$, which was the incidence rate expected based on the Korean PONV model, indicating that the use of ondansetron alone is not sufficient to reduce the PONV incidence rate. It was also reported that the multimodal approach, where various antiemetics are mixed and injected or antiemetics are combined with total intravenous anesthesia, was more effective in preventing PONV in PONV high-risk groups $[22,23]$. Hence, there has been increasing attention to the combined administration of ondansetron with other antiemetics for the effective prevention of PONV.

Since the antiemetic effect of midazolam, which is used for premedication or as an auxiliary drug for induction, in expectation of sedation, amnesia, and anxiolytic effect, has been established, various studies on it have been reported recently. Ha et al. [24] reported that $0.075 \mathrm{mg} / \mathrm{kg}$ of midazolam injected into patients who had undergone thyroidectomy was as effective as $4 \mathrm{mg}$ of ondansetron in preventing PONV without delay in the recovery time. Jung and Jeon [8] reported that, among patients who had undergone total abdominal hysterectomy, IVPCA combined with $0.4 \mathrm{mg}$ of midazolam per $1 \mathrm{mg}$ of morphine showed a significantly lower PONV incidence rate than that of the IV-PCA with just morphine. The antiemetic mechanism of midazolam has not been full elucidated. Its anxiolytic effect as well as the intensification of the adenosine effect by repressing the adenosine reabsorption in the chemoreceptor trigger zone may be related to the reduced PONV incidence rate $[25,26]$. The antiemetic effect may be caused by the reduction of 5-HT secretion since midazolam binds the GABA receptor [27]. A study reported that preoperative anxiety could affect the incidence rate of PONV [28]. Thus, reducing anxiety may prevent PONV. In addition, the reason why the measured incidence rate of PONV was lower than what was expected in the recovery room might be because of the midazolam with its antiemetic effect.

In this study, a concern was that the sedative effect of midazolam would affect the recovery from the general anesthesia, but there was no difference in the OAA/S scores taken when the patients were in the recovery room, during the 6 hours after leaving the recovery room, and in the period from 6 to 24 hours after leaving recovery room (Table 4). Additionally, no patients had an OAA/S score of 3 or lower 24 hours after leaving the recovery room or had any side effects such as respiratory failure. Thus, if a higher dose of midazolam had been infused, the antiemetic effect would have been maximized.

The comparison of the VAS scores among the groups showed that there were no significant differences when the patients were in the recovery room, during the 6 hours after leaving the recovery room, and from 6 to 24 hours after. However, the ketorolac-demanding rate in the M Group was $20 \%$, which was 
lower than that of the other groups (Table 3). If midazolam and fentanyl are combined for induction, the does can be reduced when compared to the single use of an opioid, since they have a synergistic effect [29]. Even though the ketorolac and additional antiemetic demanding rate was higher in the MO group than that of the other groups, the results of the $\mathrm{M}$ group indicate that the synergistic effect of midazolam and fentanyl may have an effect on the fentanyl demand and on the incidence rate of PONV. If the number of IV-PCA bolus injections had been measured, it could have been determined whether the fentanyl demand decreased because of the administration of the midazolam, and whether the increased fentanyl demand affected the incidence rate of PONV as the number of IVPCA bolus injections increased; this is a limitation of this study. Additionally, if the effect of the respective antiemetics combined with the IV-PCA had been followed up for more than one day, a more meaningful result would have been produced. Although it is expected that the PONV preventing effect of the additional midazolam injection may be reduced over time following surgery, a more significant result would have been obtained if the study population was larger.

In conclusion, midazolam administration combined with IV-PCA was effective in reducing the immediate postoperative incidence rate of PONV and the mixed administration of ondansetron and midazolam combined with IV-PCA was more effective in reducing the incidence rate of PONV.

\section{References}

1. Watcha MF, White PF. Postoperative nausea and vomiting. Its etiology, treatment, and prevention. Anesthesiology 1992; 77: 16284.

2. Kim DH, Cho DH, Park CH. The Effect of timing of ondansetron administration on nausea and vomiting during intravenous patientcontrolled analgesia. Korean J Anesthesiol 2001; 41: 33-8.

3. Larijani GE, Gratz I, Afshar M, Minassian S. Treatment of postoperative nausea and vomiting with ondansetron: a randomized, double-blind comparison with placebo. Anesth Analg 1991; 73: 246-9.

4. Davies PR, Warwick P, O'Connor M. Antiemetic efficacy of ondansetron with patient-controlled analgesia. Anaesthesia 1996; 51: 880-2.

5. Dresner M, Dean S, Lumb A, Bellamy M. High-dose ondansetron regimen vs droperidol for morphine patient-controlled analgesia. Br J Anaesth 1998; 81: 384-6.

6. Cho SY, Oh MK, Yeom JH, Shin WJ, Kim YC, Lee DH. The postoperative antiemetic effect of midazolam in patients undergoing appendectomy. Korean J Anesthesiol 1999; 37: 1095-100.

7. Splinter WM, MacNeill HB, Menard EA, Rhine EJ, Roberts DJ, Gould MH. Midazolam reduces vomiting after tonsillectomy in children. Can J Anaesth 1995; 42: 201-3.

8. Jung SH, Jeon YH. Antiemetic effect of midazolam added to patientcontrolled analgesia after total abdominal hysterectomy. Korean J
Anesthesiol 2006; 51: 591-7.

9. Stewart JT, Warren FW, King DT, Venkateshwaran TG, Fox JL. Stability of ondansetron hydrochloride and 12 medications in plastic syringes. Am J Health Syst Pharm 1998; 55: 2630-4.

10. Chiaretti A, Genovese O, Antonelli A, Tortorolo L, Ruggiero A, Focarelli B, et al. Patient-controlled analgesia with fentanil and midazolam in children with postoperative neurosurgical pain. Childs Nerv Syst 2008; 24: 119-24.

11. Chernik DA, Gillings D, Laine H, Hendler J, Silver JM, Davidson $\mathrm{AB}$, et al. Validity and reliability of the Observer's Assessment of Alertness/Sedation scale: study with intravenous midazolam. J Clin Psychopharmacol 1990; 10: 244-51.

12. Park SK, Cho EJ. A randomized, double-blind trial of palonosetron compared with ondansetron in preventing postoperative nausea and vomiting after gynaecological laparoscopic surgery. J Int Med Res 2011; 39: 399-407.

13. Kim EJ, Ahn HJ, Park SH, Bang SR, Choi DH. Risk factors of postoperative nausea and vomiting: development of Korean risk model. Korean J Anesthesiol 2005; 48: 380-6.

14. Sinclair DR, Chung F, Mezei G. Can postoperative nausea and vomiting be predicted? Anesthesiology 1999; 91: 109-18.

15. Walder B, Schafer M, Henzi I, Tramer MR. Efficacy and safety of patient-controlled opioid analgesia for acute postoperative pain. A quantitative systematic review. Acta Anaesthesiol Scand 2001; 45: 795-804.

16. Tramer MR, Walder B. Efficacy and adverse effects of prophylactic antiemetics during patient-controlled analgesia therapy: a quantitative systematic review. Anesth Analg 1999; 88: 1354-61.

17. Scholz J, Steinfath M, Tonner PH. Antiemetics. In: Anesthetic pharmacology. Edited by Evers AS, Maze M. Philadelphia, Churchill Livingstone. 2004, pp 777-91.

18. Boonmak P, Boonmak S, Bunsaengjaroen P, Srichaipanha S, Poomsawat S, Nonlhaopol D. Antiemetic effect of ondansetron 0.2 mg mL-1 in PCA morphine solution. Eur J Anaesthesiol 2007; 24: 664-7.

19. Hwang K, Shim K, Lee S, Kim H. The effect of continuous infusion of ondansetron on nausea and vomiting during intravenous patientcontrolled analgesia. Korean J Anesthesiol 2004; 47: 830-3.

20. Kil HJ, Lee SY, Lee YS, Kim JS, Han SG, Choi MH, et al. A comparison of the efficacy and safety of ondansetron, droperidol and ondansetron plus droperidol as antiemetics for elective thyroidectomy. Korean J Anesthesiol 1999; 36: 834-40.

21. Tramer MR, Reynolds DJ, Moore RA, McQuay HJ. Efficacy, doseresponse, and safety of ondansetron in prevention of postoperative nausea and vomiting: a quantitative systematic review of randomized placebo-controlled trials. Anesthesiology 1997; 87: 1277-89.

22. Hammas B, Thorn SE, Wattwil M. Superior prolonged antiemetic prophylaxis with a four-drug multimodal regimen - comparison with propofol or placebo. Acta Anaesthesiol Scand 2002; 46: 232-7.

23. Eberhart LH, Mauch M, Morin AM, Wulf H, Geldner G. Impact of a multimodal anti-emetic prophylaxis on patient satisfaction in highrisk patients for postoperative nausea and vomiting. Anaesthesia 2002; 57 : 1022-7.

24. Ha JH, Kwak KH, Seo JW, Lee SH, Park SS, Baek WE. Effectiveness of ondansetron and midazolam in the prevention of PONV after thyroidectomy. Korean J Anesthesiol 2007; 53: 344-9. 
25. Phillis JW, Siemens RK, Wu PH. Effects of diazepam on adenosine and acetylcholine release from rat cerebral cortex: further evidence for a purinergic mechanism in action of diazepam. Br J Pharmacol 1980; 70: 341-8.

26. Phillis JW, Bender AS, Wu PH. Benzodiazepines inhibit adenosine uptake into rat brain synaptosomes. Brain Res 1980; 195: 494-8.

27. Racke K, Schworer H, Kilbinger H. Effects of the benzodiazepine receptor agonist midazolam and antagonist flumazenil on 5-hydroxytryptamine release from guinea-pig intestine in vitro. Indirect support for a "natural" benzodiazepine-like substance in the intestine. Naunyn Schmiedebergs Arch Pharmacol 1990; 341: 1-7.

28. Van den Bosch JE, Moons KG, Bonsel GJ, Kalkman CJ. Does measurement of preoperative anxiety have added value for predicting postoperative nausea and vomiting? Anesth Analg 2005; 100: 1525-32.

29. Ben-Shlomo I, abd-el-Khalim H, Ezry J, Zohar S, Tverskoy M. Midazolam acts synergistically with fentanyl for induction of anaesthesia. Br J Anaesth 1990; 64: 45-7. 